\title{
FORAGING BEHAVIOR
}




\title{
FORAGING BEHAVIOR
}

Edited by

\author{
Alan C. Kamil \\ University of Massachusetts \\ Amherst, Massachusetts \\ John R. Krebs \\ Oxford University \\ Oxford, England \\ and \\ H. Ronald Pulliam \\ University of Georgia \\ Athens, Georgia
}


Library of Congress Cataloging in Publication Data

Foraging behavior.

Based on a conference on foraging behavior which was held in June, 1984, in Providence, R.I.

Bibliography: p.

Includes index.

1. Animals-Food-Congresses. I. Kamil, Alan C. II. Krebs, John, R. III. Pulliam, H. Ronald.

QL756.5.F66 1987

591.53

87-6951

ISBN-13: 978-1-4612-9027-8

DOI: $10.1007 / 978-1-4613-1839-2$

(C) 1987 Plenum Press, New York

Softcover reprint of the hardcover 1st edition 1987

A Division of Plenum Publishing Corporation

233 Spring Street, New York, N.Y. 10013

All rights reserved

No part of this book may be reproduced, stored in a retrieval system, or transmitted in any form or by any means, electronic, mechanical, photocopying, microfilming, recording, or otherwise, without written permission from the Publisher 


\section{PREFACE}

Foraging behavior has always been a central concern of ecology. Understanding what animals eat is clearly an essential component of understanding many ecological issues including energy flow, competition and adaptation. Theoretical and empirical developments in the late 1960's and 1970 's led to a new emphasis in the study of foraging behavior, the study of individual animals in both field and laboratory. This development, in turn, led to an explosion of interest in foraging. Part of the reason for this explosion is that when foraging is studied at the individual level, it is relevant to many disciplines. Behaviorists, including ethologists and psychologists, are interested in any attempt to understand behavior. Ecologists know that a better understanding of foraging will contribute to resolving a number of important ecological issues. Anthropologists and others are applying the ideas coming out of the study of foraging behavior to problems within their disciplines.

These developments led to a multidisciplinary symposium on foraging behavior, held as part of the 1978 Animal Behavior Society meetings in Seattle, Washington. Many ecologists, ethologists and psychologists participated or attended. The symposium was very successful, generating a high level of excitement. As a result, the participants decided to publish the proceedings of the symposium (Kamil \& Sargent 1981).

The authors of chapters for that volume also decided to forego the usual royalties. These moneys were placed in a fund and used to finance a conference on foraging behavior which was held in June, 1984, in Providence, Rhode Island. Brown University, with Doug Morse in charge of local arrangements, provided an ideal setting for the conference. The conference was advertised, and an open call for papers published in various newsletters. As a result, almost 100 abstracts were submitted for consideration for inclusion on the program. In addition, three papers were invited, from James Gould, John Staddon and Robert May. The final program included 27 
regular papers, and 24 poster presentations, selected by a program committee consisting of the editors of this volume.

The chapters in this book are based primarily on papers delivered at the conference. All participants were invited to submit papers, and most did so. In addition, a few papers were solicited to review areas that were not adequately covered by the submitted papers. All papers were reviewed, and most were revised.

In putting this volume together, the editors have attempted to keep in mind the special nature of collected volumes. Although collected volumes are often held in low esteem, they can serve useful purposes, if properly constructed. Two purposes are especially appropriate. (1) To provide a forum for broad reviews of either research programs or research areas and (2) to provide a forum for new ideas. As in the first book, the editors have encouraged several different types of papers. There are reviews of the literature, reviews of research programs or approaches to problems, and thought pleces. As in the case of the first book, we hope that the current volume will serve several different audiences well. For the student just beginning to study foraging behavior, the book should serve as a good introduction to the field. For the researcher primarily interested in other topics, but with a peripheral interest in foraging, the volume should serve as a convenient guide to current issues and problems. And for the researcher in the field, it should be a useful reference.

Despite these similarities with the Kamil \& Sargent volume, there is one big difference: the field has changed dramatically between the late 1970 's and the mid 1980's. As documented in the papers by Gray and Schoener in the first section of the book, the sheer size of the literature on foraging behavior in general, including optimal foraging theory (OFT), has increased enormously. Along with this increase in size has come an increase in scope. While it was possible to list just a few topics in the introduction to the 1981 volume, the listing today is much longer. And many of the issues are more complex. This reflects natural and healthy growth, but it made the editorial task more difficult.

Perhaps the most difficult aspect of assembling this book was deciding how to organize it. As the editors tried out different schemes, we found that no matter what organization we used, some papers either did not easily fit into major categories, or spanned two categories. We finally decided on a six part organization. The six sections are: (1) reviews of OFT; 
(2) diet selection; (3) patch utilization; (4) reproductive consequences of foraging behavior; (5) foraging and learning; and (6) caching and cache recovery behavior.

The study of foraging behavior is not a discipline in and of itself. Yet it is relevant to the concerns of many disciplines, including biology, ecology, psychology, anthropology and economics and sub-disciplines such as ethology, animal learning and sociobiology. The papers in this volume represent this range of relevance. Chapters discuss relationships between foraging and social behavior (e.g., Caraco, Nur, Milinski), foraging and life history strategy (e.g., Nur, Morse \& Fritz, Campbell), foraging and learning and memory (e.g., Fantino, Hanson, Staddon \& Reid, Balda, Bunch, Kamil, Sherry \& Tomback) and foraging and reproductive success (Pierotti \& Annett, Morse \& Fritz).

Many of the chapters also emphasize that there are many interesting and important questions about foraging behavior that remain to be answered. The royalties from this volume will again be used to fund another conference, in 1989 or 1990 . We look forward to meeting many of you at that future meeting, and learning the answers to many of the questions posed in this volume.

\author{
A.C. Kamil \\ J.R. Krebs \\ H.R. Pulliam
}


CONTENTS

OPTIMAL FORAGING THEORY $\ldots \ldots \ldots \ldots \ldots \ldots \ldots \ldots \ldots \ldots \ldots \ldots \ldots \ldots \ldots \ldots \ldots \ldots \ldots \ldots$

A Brief History of Optimal Foraging Ecology ................. 5

T.W. Shoener

Faith and Foraging: A Critique of the "Paradigm Argument

from Design" ................................. R.D. Gray

THE PROBLEM OF SELECTIVITY

A Test of the Energy Maximization Premise of Optimal

Foraging Theory

D.B. Campbe11

Delivering Food to a Central Place: Three Studies of

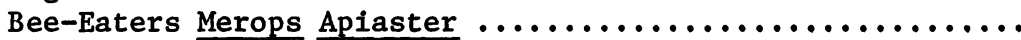

J.R. Krebs, M.I. Avery and A.I. Houston

Operant Conditioning Simulations of Foraging and the

Delay-Reduction Hypothesis .......................

E. Fantino

Foraging Behavior of Some Wintering Waders: Prey-Selection

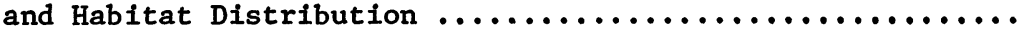
P.M. Meire

Foraging Time Constraints and Diet Choice $\ldots \ldots \ldots \ldots \ldots \ldots \ldots \ldots \ldots$ J.R. Lucas

PATCH UTILIZATION

Stochastic Models of Optimal Foraging

R.F. Green

Starlings and Optimal Foraging Theory: Modelling in a

Fractal World ................................. 303

A. Kacelink and I.C. Cuthill

Tests of Optimal Foraging Using an Operant Analogue

J. Hanson

Competition for Non-Depleting Resources: The Ideal Free

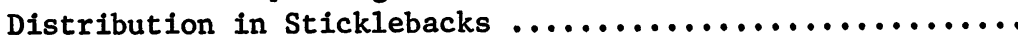
M. Milinski 
Reproductive Consequences of Dietary Specialization and

Switching in an Ecological Generalist .................

R. Pierotti and C. Annett

The Consequences of Foraging for Reproductive Success

D.H. Morse and R.S. Fritz

Parents, Nestlings and Feedings Frequency: A Model of Optimal Parental Investment and Implications for Avian Reproductive Strategies

N. Nur

LEARNING AND FORAGING

The Role of Learning in Honey Bee Foraging

J.L. Gould

Adaption to Reward ....................................

J.E.R. Staddon and A.K. Reid $\ldots \ldots \ldots \ldots \ldots \ldots \ldots \ldots \ldots$

Signal Detection Theory and Foraging for Cryptic

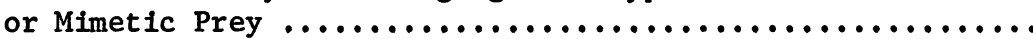

T. Getty, A.C. Kamil and Pamela G. Real

Foraging Theory and Design

J.G. Ollason

Should Foragers Remember Where They've Been? Explorations of a Simulation Model Based on the Behavior and Energetics of Territorial Hummingbirds ............... D.P. Armstrong, C.L. Gass and G.D. Sutherland

Randon and Systematic Foraging, Experimental Studies of Depletion and Schedules of Reinforcement $\ldots \ldots \ldots \ldots \ldots \ldots$ W.M. Baum

Cache-Protecting Behavior of Food-Hoarding Animals

S.B. Vander Wall and K,G. Smith

Cache Site Memory in Birds

R.P. Balda, K.G. Bunch, A.C. Kamil, D.F. Sherry

and D.F. Tomback 